\title{
Causes of death from the randomized CoreValve US Pivotal High-Risk Trial
}

\author{
Vincent Gaudiani, MD, ${ }^{\mathrm{a}}$ G. Michael Deeb, MD, ${ }^{\mathrm{b}}$ Jeffrey J. Popma, MD, ${ }^{\mathrm{c}}$ David H. Adams, MD, ${ }^{\mathrm{d}}$
}

Thomas G. Gleason, MD, ${ }^{e}$ John V. Conte, MD,${ }^{f}$ George L. Zorn III, MD, ${ }^{g}$ James B. Hermiller, Jr, MD, ${ }^{\mathrm{h}}$ Stan Chetcuti, MD, ${ }^{\mathrm{d}}$ Mubashir Mumtaz, MD, ${ }^{\mathrm{i}}$ Steven J. Yakubov, MD, ${ }^{\mathrm{j}}$ Neal S. Kleiman, MD, ${ }^{\mathrm{k}}$ Jian Huang, MD, ${ }^{1}$ and Michael J. Reardon, $\mathrm{MD}^{\mathrm{k}}$

\section{ABSTRACT}

Objective: Explore causes and timing of death from the CoreValve US Pivotal High-Risk Trial.

Methods: An independent clinical events committee adjudicated causes of death, followed by post hoc hierarchical classification. Baseline characteristics, early outcomes, and causes of death were evaluated for 3 time periods (selected based on threshold of surgical 30-day mortality and on the differences in the continuous hazard between the 2 groups): early (0-30 days), recovery (31-120 days), and late (121-365 days).

Results: Differences in the rate of death were evident only during the recovery period (31-120 days), whereas 15 patients undergoing transcatheter aortic valve replacement (TAVR) $(4.0 \%)$ and 27 surgical aortic valve replacement (SAVR) patients $(7.9 \%)$ died $(P=.025)$. This mortality difference was largely driven by higher rates of technical failure, surgical complications, and lack of recovery following surgery. From 0 to 30 days, the causes of death were more technical failures in the TAVR group and lack of recovery in the SAVR group. Mortality in the late period (121-365 days) in both arms was most commonly ascribed to other circumstances, comprising death from medical complications from comorbid disease.

Conclusions: Mortality at 1 year in the CoreValve US Pivotal High-Risk Trial favored TAVR over SAVR. The major contributor was that more SAVR patients died during the recovery period (31-121 days), likely affected by the overall influence of physical stress associated with surgery. Similar rates of technical failure and complications were observed between the 2 groups. This suggests that early TAVR results can improve with technical refinements and that high-risk surgical patients will benefit from reducing complications. (J Thorac Cardiovasc Surg 2017;153:1293-301)

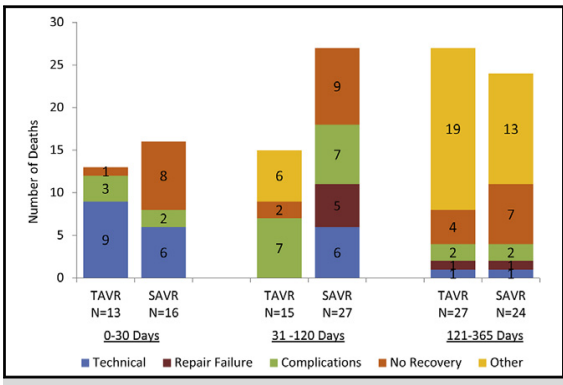

Hierarchical causes of death in TAVR and SAVR patients for the 3 time periods.

\section{Central Message}

Differences in survival between TAVR and SAVR in high-risk patients appear to be driven primarily by issues with disease repair and patient recovery from SAVR.

\section{Perspectives}

Self-expanding transcatheter aortic valve replacemen has shown superior survival versus surgical aortic valve replacement. We examined death details for patients who died up to 1 year after aortic valve replacement, and found differences in survival only in the 31- to 120-day period favoring transcatheter aortic valve replacement. Surgical aortic valve failure to repair the $\mathrm{AV}$ disease and lack of recovery from surgical insult mainly accounted for this difference. Death due to complications was similar in both groups.

See Editorial Commentary page 1302.

See Editorial page 1291.

\footnotetext{
From the a Department of Thoracic and Cardiac Surgery, El Camino Hospital, Mountain View, Calif; ${ }^{b}$ Department of Cardiovascular Surgery, University of Michigan Hospitals, Ann Arbor, Mich; ${ }^{\mathrm{c} D e p a r t m e n t ~ o f ~ I n t e r v e n t i o n a l ~ C a r d i o l o g y, ~ B e t h ~ I s r a e l ~}$ Deaconess Medical Center, Boston, Mass; ${ }^{\mathrm{d}}$ Department of Cardiovascular Surgery,

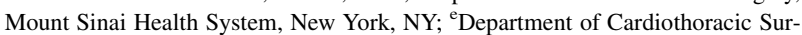
gery, University of Pittsburgh, Pittsburgh, Pa; ${ }^{\mathrm{f}}$ Division of Cardiac Surgery, Johns Hopkins Hospital, Baltimore, Md; ${ }^{\mathrm{g}}$ Cardiovascular Research Institute, University of Kansas, Kansas City, Kan; ' Interventional Cardiology, St Vincent Medical Center, Indianapolis, Ind; i Department of Cardiovascular Surgery, Pinnacle Health, Harrisburg, Pa; ${ }^{\mathrm{j}}$ Interventional Cardiology, Riverside Methodist Hospital, Columbus, Ohio; ${ }^{\mathrm{k}}$ Department of Cardiothoracic Surgery, Houston Methodist DeBakey Heart \& Vascular Center, Houston, Tex; and ${ }^{\mathrm{l} B i o s t a t i s t i c a l ~ S e r v i c e s, ~ M e d t r o n i c, ~}$ Minneapolis, Minn.
}

Supported by Medtronic, Minneapolis, Minn.

Read at the 96th Annual Meeting of The American Association of Thoracic Surgery, Baltimore, Maryland, May 14-18, 2016.

Received for publication May 25, 2016; revisions received Nov 14, 2016; accepted for publication Nov 18, 2016; available ahead of print Feb 26, 2017.

Address for reprints: Vincent Gaudiani, MD, Pacific Coast Cardiac \& Vascular Surgeons, 2900 Whipple Ave, Redwood City, CA 94062 (E-mail: Vgaudiani@ Pccvs.com)

$0022-5223 / \$ 36.00$

Copyright (C) 2017 by The American Association for Thoracic Surgery

http://dx.doi.org/10.1016/j.jtcvs.2016.11.069 


\section{Abbreviations and Acronyms \\ AS = aortic stenosis \\ CEC $=$ clinical events committee \\ NYHA $=$ New York Heart Association \\ PPM = patient prosthesis mismatch \\ SAVR = surgical aortic valve replacement \\ STS-PROM $=$ Society of Thoracic Surgeons Predictor of Mortality \\ TAVR $=$ transcatheter aortic valve replacement}

Scanning this QR code will take you to a supplemental video for the article. To view the AATS 2016 Webcast, see the URL next to the video thumbnail.

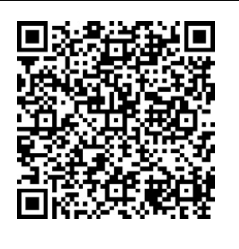

Symptomatic severe aortic stenosis (AS) is a disease with dismal survival without relief of the obstruction. ${ }^{1}$ Surgical aortic valve replacement (SAVR) has been used for almost 6 decades for this purpose and is arguably among the most successful cardiac surgical procedures available. ${ }^{2,3}$ This has led to SAVR being an American College of Cardiology/American Heart Association class I indication in the treatment of symptomatic severe AS. ${ }^{4}$ Despite this success, one-third to one-half of patients with symptomatic severe AS do not receive SAVR due to advanced age, perceived high risk, hostile anatomy, or patient refusal. ${ }^{5-7}$ Transcatheter aortic valve replacement (TAVR) was introduced as a less-invasive approach to treating AS to close this gap in patients not receiving treatment. Since the first self-expanding TAVR was performed in 2004 by Grube and LaBorde, ${ }^{8}$ more than 100,000 cases have been performed in more than 60 countries. This rapid growth has been fueled in part by the results seen in the CoreValve US Pivotal Trials. In the extreme-risk population, TAVR was shown to be superior to standard therapy for death or major stroke. ${ }^{9}$ In the high-risk randomized trial, TAVR was also shown to be superior to SAVR through 2 years, ${ }^{10,11}$ and continued to show a survival advantage at 3 years. ${ }^{12}$ Because this is the only randomized trial to show superiority of self-expanding TAVR versus SAVR in high-risk patients, we chose to examine the timing and causes of death to further understand the differences between treatment groups and survival.

\section{METHODS \\ Study Design}

The CoreValve US Pivotal High-Risk Trial was a multicenter, randomized, noninferiority trial performed at 45 sites in the United States; the trial design and outcomes through 3 years have been reported. ${ }^{12}$
Patients deemed to be at high surgical risk were randomized 1:1 to either TAVR with the CoreValve self-expanding bioprosthesis (Medtronic, Minneapolis, Minn) or to SAVR, with valve selection based on operator preference. An independent clinical events committee (CEC) adjudicated all major clinical events, including cause of death, and study oversight was provided by an independent data safety monitoring board. All patients provided written informed consent for follow-up evaluations to 5 years. Clinical Trial Registration (ClinicalTrials.gov): NCT01240902.

The first draft of the manuscript was written by the first and senior authors. All the other authors then critically reviewed the manuscript and all approved the decision to submit the manuscript for publication. The accuracy and completeness of the data and all related analyses and study adherence to protocol were confirmed by all authors.

\section{Patient Selection}

Patient selection and detailed inclusion and exclusion criteria have been previously described. ${ }^{10}$ In brief, patients with severe, symptomatic (New York Heart Association [NYHA] functional class II or worse) aortic stenosis were considered eligible for the trial if considered at increased risk for heart surgery by both the local heart team and a national screening committee. High risk was defined as an expected 30-day risk of mortality of at least $15 \%$ but $<50 \%$. Each site calculated the Society of Thoracic Surgeons Predictor of Mortality (STS-PROM) using the STS calculator and submitted the form to the screening committee. The sponsor (Medtronic) ensured the accuracy of the documentation. The STS-PROM score and other factors previously described ${ }^{10}$ were used in assessing this risk.

\section{Procedural Details}

The TAVR implant procedure and the CoreValve System have been previously described in detail. ${ }^{10}$ Most TAVR procedures were performed in hybrid operating rooms under general anesthesia with transesophageal echocardiography. Left subclavian and direct aortic accesses were allowed and detailed techniques have been described elsewhere. ${ }^{13}$ SAVR was performed using site-specific standard techniques with surgeon's choice of valve. Valve size selection was based on multidetector computed tomography angiography. For TAVR, dual antiplatelet therapy with aspirin and clopidogrel was recommended for 3 months postprocedure.

\section{Objectives}

We evaluated all-cause mortality through 1 year based on 3 time periods: 0 to 30 days (early), 31 to 120 days (recovery), and 121 to 365 days (late). The independent CEC assigned the cause of death as cardiovascular, sorted into 12 causes, including “other," or noncardiovascular, sorted by 7 causes, including "other." Because patients often have multiple factors contributing to their cause of death, 3 of the authors (V.A.G., M.J.R., and G.M.D.) reviewed all death narratives and additionally categorized the deaths in a hierarchical fashion based on what was perceived to likely be the initiating factor, as well as in decreasing order of ability to correct in the future (Table 1). Baseline demographic characteristics, frailties, comorbidities, and disabilities as well as procedural outcomes and their relationship to mortality were examined. Disposition at discharge and its relationship to mortality were examined. Echocardiography assessment of the effective orifice area for calculation of patient-prosthesis mismatch (PPM) was centrally analyzed (Echocardiography Core Laboratory, Mayo Clinic, Rochester, Minn).

\section{Statistical Analysis}

The analysis cohort for this exploratory study of a randomized trial was the as-treated population, which comprised all randomized patients with an attempted implant procedure, and all patients were analyzed according to their first attempted procedure.

Categorical variables were presented as numbers and percentages and compared with Fisher exact test or the $\chi^{2}$ test where appropriate. Continuous variables were presented as means \pm standard deviation and 
TABLE 1. Hierarchical classification of causes of death

Technical problems with the procedure
Injury to cardiac structure
Lack of myocardial protection
Induced ischemia
Vascular complication requiring intervention and transfusion of $>3$ units
Failure to repair disease adequately
Mean gradient $>20$ mm $\mathrm{Hg}$
Moderate or greater paravalvular leak
Failure to correct known significant coronary issues
Complications (linked to death)
Acute kidney injury
Major or life threatening bleeding with transfusion
New atrial fibrillation which does not resolve by discharge
Failure to recover
Not able to spend $\geq 14$ consecutive days at home (or where you started
$\quad$ from)
Other cause not directly related to the procedure or disease repair
Malignancy
Late falls
Late surgeries
Accidents

compared with the Student $t$ test. To evaluate all-cause mortality through 1 year for the 3 time periods, the all-cause mortality rates were calculated based on the number of deaths that occurred during a time period divided by the number of patients who were at risk at the beginning of the time period (alive at the beginning of the time period). For each time period, baseline characteristics and procedural outcomes were compared between those who died and survived.

The instantaneous hazard function was estimated from the nonparametric Kaplan-Meier survival function using the Epanechnikov kernel smoothing method with a bandwidth of 25 grid points. All statistical analyses were performed with the use of SAS software, version 9.2 (SAS Institute, Cary, NC).

\section{RESULTS}

\section{Patient Flow and Baseline Characteristics}

Overall baseline characteristics have been previously reported. ${ }^{10}$ In brief, the mean age was $83.2 \pm 6.7$ years and $53 \%$ were men. Most patients ( $86.1 \%$ ) had NYHA functional class III or IV symptoms. The overall average STS-PROM was $7.4 \% \pm 3.2 \%$. By chance, the presence of diabetes mellitus in this randomized trial was lower in the TAVR group $(34.9 \%$ vs $45.4 \% ; P=.003)$; however, there were no significant differences between groups by insulin requirements. A Charlson score of 5 or greater was present in $55.8 \%$ of patients. The $5-\mathrm{m}$ gait speed was greater than $6 \mathrm{~s}$ in $79.7 \%$ of patients, and $10.3 \%$ did not live independently.

The risk of death through 1 year revealed different patterns of risk based on time since valve replacement (Figure 1). This instantaneous hazard function served as the basis for the choice of the 3 time periods studied. The baseline and procedural characteristics that were significantly different between patients who died and those who survived in the TAVR and SAVR groups for the 3 time periods are shown in Table E1.

\section{Early Mortality (0-30 Days)}

There was no difference in the number of TAVR versus SAVR patients who died during the first 30 days postprocedure (13 [3.3\%] vs $16[4.5 \%] ; P=.422)$. The mean age of patients who died versus survived was $85.5 \pm 7.3$ versus $83.1 \pm 7.1$ years $(P=.232)$ for TAVR and $84.2 \pm 6.9$ versus $83.2 \pm 6.3$ years $(P=.548)$ for SAVR. The mean STS-PROM for patients who died versus survived was $9.4 \% \pm 4.7 \%$ versus $7.2 \% \pm 2.9 \%(P=.119)$ for TAVR and $9.1 \% \pm 4.7 \%$ versus $7.5 \% \pm 3.3 \%(P=.179)$ for SAVR. The only significant baseline differences between patients who died versus survived during this early time period were more peripheral vascular disease and recent falls in the TAVR group, and a higher rate of pre-existing pacemaker for the SAVR group (Table E1). Information on the duration of pacemaker implantation was not available.

All deaths that occurred during the first 30 days were deemed due to cardiovascular causes by the CEC. Using our hierarchical categorization, almost all TAVR deaths were related to technical complications and most SAVR deaths were related to early complications (Table 2).

Mortality in the TAVR group was not related to anesthesia type, access route, valve size, valve delivery time, or total procedure time. More TAVR patients who died compared with those who survived required a second TAVR (3 out of 13 [23.1\%] vs 11 out of 378 [2.9\%]; $P=.009$ ), underwent conversion to surgery (2 out of 13 [15.4\%] vs 0 out of $378[0.0 \%] ; P=.001$ ), had coronary artery compromise ( 1 out of $13[7.7 \%]$ vs 0 out of 378 $[0.0 \%] ; P=.033$ ), or required the valve to be retrieved ( 3 out of $13[23.1 \%]$ vs 8 out of 378 [2.1\%]; $P=.004)$. We noted that 4 of the 9 TAVR patients who died due to technical complications had moderate or severe paravalvular leak during the procedure. In 2 patients, implantation of a second valve was performed (noted above), 1 patient was treated with a post-TAVR balloon valvuloplasty and attempted SAVR that was unsuccessful and the patient died during the procedure, and 1 patient underwent SAVR and died 3 weeks later. There were no differences in the methods of surgical access, valve size or type, total procedure time, total blood products given in the operating room, cardiopulmonary bypass duration, or aortic crossclamp time between SAVR patients who died and those who survived during the recovery period.

\section{Recovery Period (31-120 Days)}

During the recovery period of 31 to 120 days, 15 TAVR patients $(4.0 \%)$ died compared with 27 SAVR patients $(7.9 \%)(P=.025)$. The number of cardiovascular deaths adjudicated by the CEC were $12(3.2 \%)$ for TAVR and 16 $(4.7 \%)$ for SAVR $(P=.297)$, with a larger proportion of cardiovascular deaths in the TAVR group (12 out of 15 


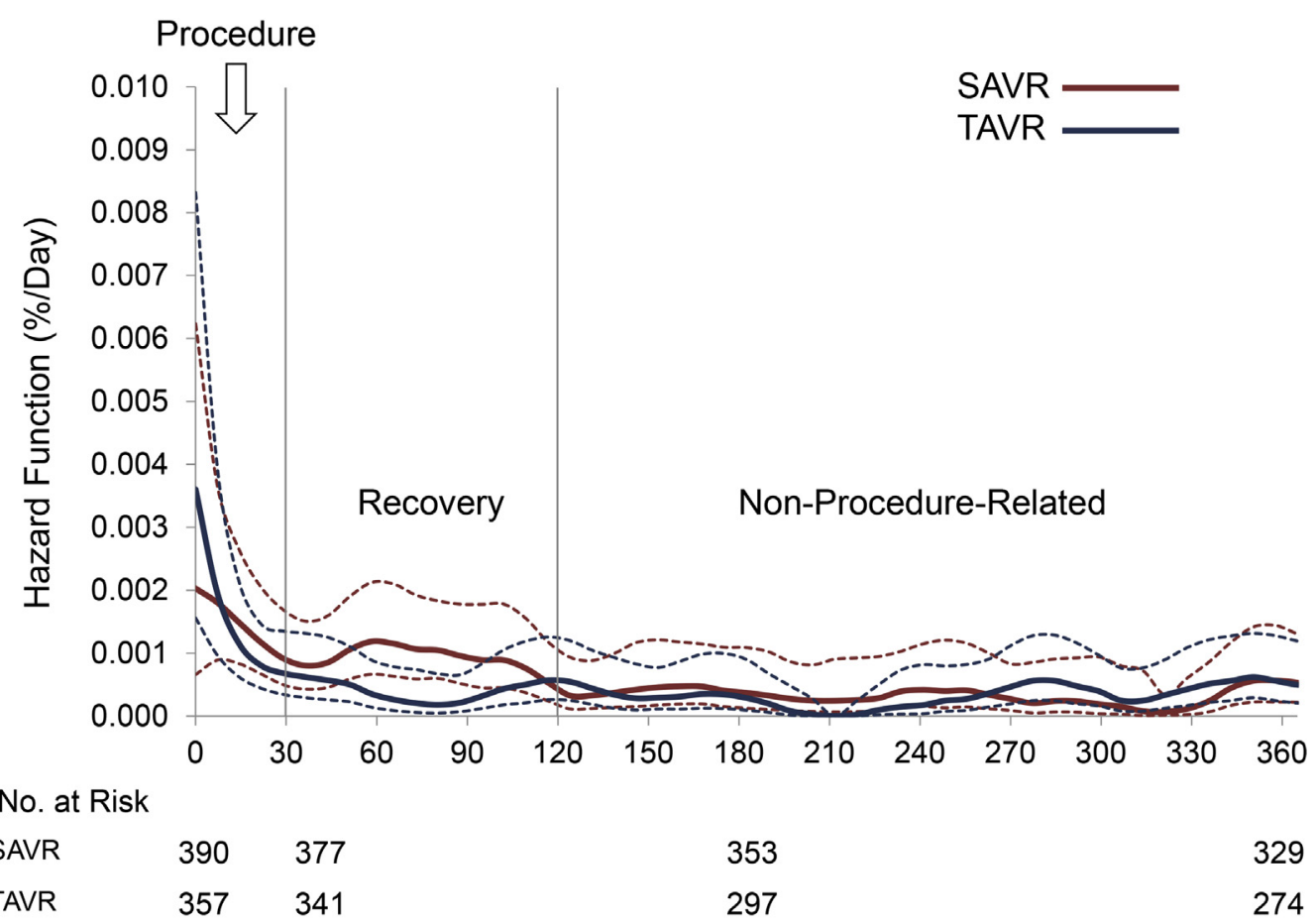

FIGURE 1. Instantaneous hazard of all-cause mortality. The estimated hazard for transcatheter aortic valve replacement (TAVR) patients (blue lines) and surgical aortic valve replacement (SAVR) patients (red lines) through 1 year. Dashed lines represented 95\% confidence intervals.

[80.0\%] vs 16 out of 27 [59.3\%]) than in the SAVR group. The CEC determined that 3 TAVR deaths and 11 SAVR deaths $(0.8 \%$ vs $3.2 \% ; P=.028)$ were due to noncardiovascular causes. The 3 noncardiovascular deaths in the TAVR group were due to infection or sepsis $(\mathrm{n}=2)$ and malignancy $(\mathrm{n}=1)$. For the SAVR group, the 11 noncardiovascular causes of death were malignancy $(n=1)$, infection or sepsis $(n=6)$, chronic obstructive pulmonary disease $(n=1)$, and other $(n=3)$. Although these deaths were adjudicated as noncardiovascular by the CEC, our review showed that some of these patients had never really recovered from the initial procedure.

The significant differences in mortality between treatment groups only occurred during this recovery period of 31 to 120 days postprocedure.

Using our hierarchical scheme, the same numbers of deaths in each group were related to complications, but there were more patients categorized as failure to repair, and more patients who failed to recover, in the SAVR group (Figure 2). The same number of technical deaths occurred in the SAVR group during the early and recovery time periods. The 6 TAVR patients we categorized as dying from other causes were due to sudden death $(\mathrm{n}=1)$; pancreatic cancer $(\mathrm{n}=1)$; pulseless electrical activity $(\mathrm{n}=1)$; diastolic failure $(\mathrm{n}=1)$; endocarditis, with history of liver transplant $(\mathrm{n}=1)$; and 1 from unknown causes. Significant baseline differences between those who died and survived are shown in Table E1.

\section{Late (121-365 Days)}

There was no difference in the number of deaths for TAVR versus SAVR patients during the latest time period studied (27 $[7.5 \%]$ vs $24[7.7 \%] ; P=.918)$. There was also no difference in the number of CEC-adjudicated cardiovascular deaths for TAVR versus SAVR (16 [4.4\%] vs $13[4.2 \%] ; P=.865)$. Hierarchical causes of death were primarily due to other reasons, deemed unrelated to the initial aortic valve replacement (Table 1). Several baseline differences were present for those who died compared with those who survived during this late period (Table E1). These comorbid conditions are likely associated with the higher percentage of deaths due to other causes during this late time period.

\section{Discharge Disposition}

More TAVR patients were discharged to home compared with SAVR patients (253 [66.9\%] vs 137 [39.7\%]; $P<.001)$. Table 3 shows the distribution of discharge locations.

\section{PPM}

PPM was defined as an indexed effective orifice area $\leq 0.85 \mathrm{~cm}^{2} / \mathrm{m}^{2}$. We were not able to show any statistically significant differences in the incidence of PPM in patients who died versus those who survived for either treatment group for any of the 3 time periods. The low number of 
TABLE 2. Number of deaths based on clinical event committee and hierarchical causes

\begin{tabular}{|c|c|c|c|c|c|c|}
\hline \multirow[b]{2}{*}{ Number of deaths } & \multicolumn{2}{|c|}{$\mathbf{0 - 3 0 ~ d ~}$} & \multicolumn{2}{|c|}{$31-120 \mathrm{~d}$} & \multicolumn{2}{|c|}{$121-365 d$} \\
\hline & $\begin{array}{c}\text { TAVR } \\
(\mathbf{n}=\mathbf{1 3})\end{array}$ & $\begin{array}{c}\text { SAVR } \\
(n=16)\end{array}$ & $\begin{array}{c}\text { TAVR } \\
(\mathbf{n}=\mathbf{1 5})\end{array}$ & $\begin{array}{c}\text { SAVR } \\
(\mathbf{n}=\mathbf{2 7})\end{array}$ & $\begin{array}{c}\text { TAVR } \\
(\mathbf{n}=\mathbf{2 7})\end{array}$ & $\begin{array}{c}\text { SAVR } \\
(n=24)\end{array}$ \\
\hline \multicolumn{7}{|l|}{ Clinical event committee-adjudicated causes } \\
\hline All-cause & 13 & 16 & 15 & 27 & 27 & 24 \\
\hline Cardiovascular & 13 & 16 & 12 & 16 & 16 & 13 \\
\hline Valve-related & 9 & 2 & 4 & 2 & 8 & 3 \\
\hline Sudden/unexpected/unexplained & 1 & 1 & 1 & 2 & 4 & 3 \\
\hline Congestive heart failure/cardiogenic shock & 1 & 6 & 5 & 4 & 1 & 4 \\
\hline Myocardial infarction & 0 & 0 & 0 & 1 & 0 & 1 \\
\hline Arrhythmia & 1 & 1 & 0 & 0 & 0 & 0 \\
\hline Other & $1^{*}$ & $6 \dagger$ & 0 & 5 & 1 & 0 \\
\hline Unknown & 0 & 0 & 2 & 2 & 2 & 2 \\
\hline Noncardiovascular & NA & NA & 3 & 11 & 11 & 11 \\
\hline Malignancy & - & - & 1 & 1 & 3 & 1 \\
\hline Accidental & - & - & 0 & 0 & 0 & 1 \\
\hline Infection/sepsis & - & - & 2 & 6 & 6 & 4 \\
\hline Renal disease & - & - & 0 & 0 & 0 & 0 \\
\hline Hepatic failure & - & - & 0 & 0 & 0 & 0 \\
\hline Chronic obstructive pulmonary disease & - & - & 0 & 1 & 0 & 2 \\
\hline Other & - & - & 0 & 3 & 2 & 3 \\
\hline \multicolumn{7}{|l|}{ Hierarchical causes } \\
\hline Technical & 9 & 6 & 0 & 6 & 1 & 1 \\
\hline Failure to repair & 0 & 0 & 0 & 5 & 1 & 1 \\
\hline Complications & 3 & 2 & 7 & 7 & 2 & 2 \\
\hline Failure to recover & 1 & 8 & 2 & 9 & 4 & 7 \\
\hline Other & 0 & 0 & 6 & 0 & 19 & 13 \\
\hline
\end{tabular}

$\overline{T A V R}$, Transcatheter aortic valve replacement; SAVR, surgical aortic valve replacement; $N A$, not available. *Aspiration pneumonia. $\dagger$ Four patients died of multiorgan failure, 1 from pulmonary embolism, and 1 from ischemic bowel/septic shock.

events per time period precluded us from showing a statistically significant influence of PPM on mortality, but we have previously shown that severe PPM negatively influenced survival for both SAVR and TAVR patients. ${ }^{14}$ However, during our review it was suspected that for 5 SAVR patients who died during the recovery period due to a failure to recover, all treated with a $19-\mathrm{mm}$ or $21-\mathrm{mm}$

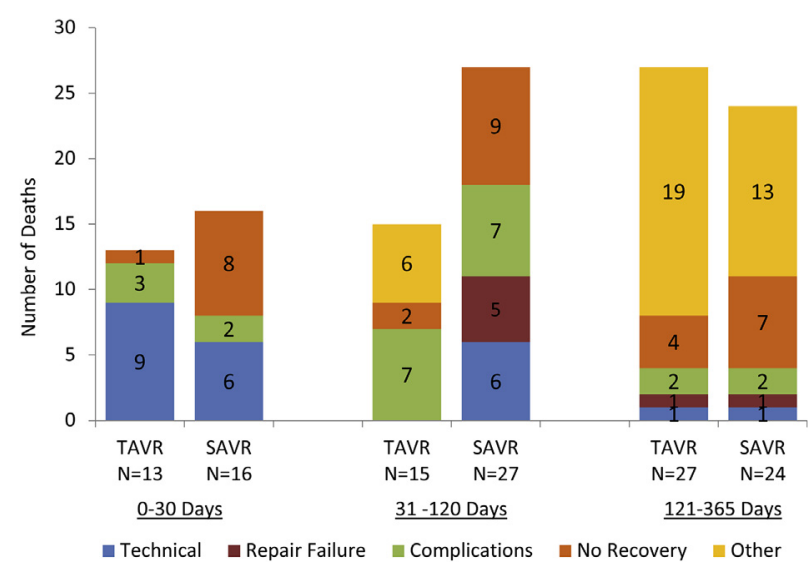

FIGURE 2. Hierarchical causes of death in transcatheter aortic valve replacement $(T A V R)$ and surgical aortic valve replacement $(S A V R)$ patients for the 3 time periods. valve, the implanted valve size could have been a contributing factor. All but 1 patient had moderate or severe PPM at follow-up, and the reviewing surgeons (V.A.G., M.J.R., and G.M.D.) believed this was the initiating event that led to death.

\section{DISCUSSION}

In this study, TAVR patients experienced significantly less mortality than SAVR patients. Most of this benefit was due to differences in mortality during the recovery period from 1 to 4 months. We believe that ours is the first study to show the superiority of an interventional technique over surgery; therefore, we investigated the details of the mortality differences in this post hoc analysis.

Both SAVR and TAVR have been shown to relieve aortic stenosis and have superior survival compared with medical therapy. ${ }^{9,15}$ TAVR has been tested against SAVR in 3 randomized trials: 2 in high-risk patients and 1 in intermediate-risk patients in the United States. ${ }^{10,16,17}$ The Placement of Aortic Transcatheter Valves A trial showed equivalent survival in SAVR up to 5 years. ${ }^{18}$ The randomized CoreValve US Pivotal High-Risk Trial showed that self-expanding TAVR had superior survival compared with SAVR at 1 year ${ }^{10}$ and at 2 years. ${ }^{11}$ This unique finding is provocative and the reason for this survival difference is 
TABLE 3. Discharge location

\begin{tabular}{lccc}
\hline \multicolumn{1}{c}{ Discharge location } & $\begin{array}{c}\text { TAVR } \\
(\mathbf{n}=\mathbf{3 9 1})\end{array}$ & $\begin{array}{c}\text { SAVR } \\
(\mathbf{n}=\mathbf{3 5 9})\end{array}$ & $\boldsymbol{P}$ value \\
\hline Number at the location & 378 & 345 & $<.0001$ \\
Home & $253(66.9)$ & $137(39.7)$ & \\
Rehabilitation clinic & $90(23.8)$ & $158(45.8)$ & \\
Another hospital & $3(0.8)$ & $11(3.2)$ & \\
Other & $32(8.5)$ & $39(11.3)$ & \\
\hline Data are presented as $\mathrm{n}(\%) . T A V R$ & Transcatheter aortic valve replacement; SAVR
\end{tabular}

Data are presented as n (\%). TAVR, Transcatheter aortic valve replacement; SAVR, surgical aortic valve replacement.

important to understanding TAVR and SAVR and improving both therapies.

Patients die after invasive procedures in different time periods and for different and often multiple reasons. Because it is often difficult and sometimes impossible to assign a single cause of death, we sorted the causes of death in a hierarchical fashion beginning with what we believed were the earliest inciting factors. Patients who died intraprocedurally or within the first 72 hours generally had a catastrophic technical issue, or were not likely to survive due to their comorbidities. For TAVR, these technical issues included cardiac perforation or complications related to valve malpositioning. Technical issues for SAVR included bleeding and other standard, early postoperative complications. These issues were uncommon in both groups but when they occurred they were the leading cause of early mortality in both groups.

The significant differences in survival between the TAVR and SAVR arms of the study are concentrated in the 1- to 4-month time period after the procedure. In this recovery period, complications and failure to recover (defined as unable to be discharged to home, or to the pre-procedure residence for at least 14 days before death) were the main drivers of mortality. Failure to spend at least 2 weeks at home before death would indicate that the patients never fully recovered from the initial procedure, and that these deaths should really be considered procedure-related, regardless of the adjudicated cause.

This study shows that many of the SAVR patients who survived the first 30 days went on to die during the recovery period because they never actually recovered from the surgical intervention. When we reviewed these 27 SAVR deaths, we determined that 5 of them occurred because the aortic stenosis had not been sufficiently relieved by the operation. Deaths due to failure to repair in the SAVR group were all related to placing a valve too small for the patient, resulting in PPM. Although showing a correlation between PPM and mortality was difficult to demonstrate even in our overall group, ${ }^{14}$ the authors noted that each of these patients required significant inotropic support in the immediate postoperative period, which appeared to be

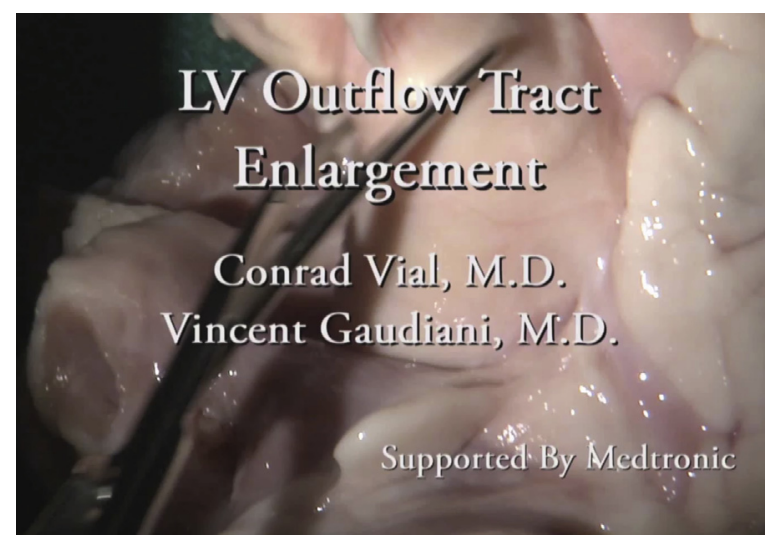

VIDEO 1. Demonstration of a left ventricular outflow tract enlargement in a porcine model. Video available at: http://www.jtcvsonline.org/article/ S0022-5223(17)30151-4/addons.

linked with the onset of organ failure. Placing a valve appropriately sized to the patient should be a priority for surgeons if we are to improve our outcomes. Most other deaths were the result of patients' inability to cope with the physical trauma of surgery. This difference is further strengthened when this cause of death is compared during the early and late time periods, when lack of recovery occurred less often in the TAVR than in the SAVR groups (Figure 2). This leads us to consider 2 implications: first, assessing mortality 30 days after a major surgery is probably insufficient, because major surgical intervention imposes significant stresses far longer than 30 days, ${ }^{19}$ and second, although surgical intervention is highly successful in patients with aortic stenosis, those with limited reserve are probably better treated with TAVR. This is supported by the fact that more TAVR patients than SAVR patients were discharged home. It is also further supported by the early return of the hazard function to baseline in the TAVR patients.

\section{Limitations}

We conducted a post hoc analysis of a randomized trial that was powered to show differences in all-cause mortality but not causes of mortality. The time periods assessed were selected based on the threshold of surgical 30-day mortality and based on the differences in the continuous hazard function between the 2 treatment groups. The assessment period of 1 to 4 months has not been previously validated. The low number of events by treatment group, and by the 3 time periods, did not allow us to make meaningful statistical comparisons. The hierarchical scheme used by the authors has not been validated elsewhere.

\section{CONCLUSIONS}

In this randomized, high-risk, self-expanding TAVR trial, more TAVR patients were alive at 1 and 2 years. $^{10,11}$ Mortality differences were due to the 
less-invasive nature of TAVR, especially in frail patients. However, many patients will continue to require SAVR. We may be able to achieve better results in these high-risk patients by optimizing valve size and reducing surgical trauma.

\section{Webcast}

You can watch a Webcast of this AATS meeting presentation by going to: http://webcast.aats.org/2016/Video/ Monday/05-16-16_Hall_E_0830_Gaudiani-800.mp4.

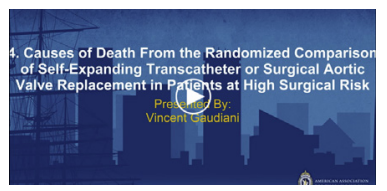

\section{Conflict of Interest Statement}

V.G. serves as a consultant and provides educational services for Medtronic, St Jude Medical, and Edwards Lifesciences. G.M.D. serves as on an advisory board and as a proctor for Medtronic, as a consultant and research investigator for Edwards Lifesciences, as a consultant and proctor for Terumo, and as a research investigator for Gore Medical. He receives no personal remunerations. J.J.P. has received institutional research grants from Medtronic, Boston Scientific, and Direct Flow Medical, and has served on a Medical Advisory Board for Boston Scientific. D.H.A. has royalty agreements through Mount Sinai School of Medicine with Edwards Lifesciences and Medtronic and has received institutional grants from Medtronic. T.G.G. receives institutional grant support from Medtronic but receives no personal income. J.V.C. serves on a surgical advisory board for Medtronic and Sorin. G.L.Z. has received consulting or proctoring fees from Medtronic and Edwards Lifesciences. J.B.H. has received fees for educational services from Medtronic. S.C. has received grant support from Edwards Lifesciences, Boston Scientific, and Medtronic, and has received proctoring fees from Medtronic. M.M. has served as a proctor; served as a consultant; and received honoraria, consulting fees, and travel reimbursements from Medtronic, Abbott, Edwards Lifesciences, and Atricure. S.J.Y. has received grant support and served on advisory boards for Medtronic and Boston Scientific, and has received grant support from Direct Flow Medical. M.J.R. and N.S.K. have received fees from Medtronic for providing educational services. J.H. is an employee and shareholder of Medtronic.

Jane Moore, MS, ELS, an employee of the sponsor, created all figures and tables, drafted the methods and results sections under the direction of the authors, and ensured the technical accuracy of the information presented.

\section{References}

1. Ross J Jr, Braunwald E. Aortic stenosis. Circulation. 1968;38(1 Suppl):61-7.

2. Schwarz F, Baumann P, Manthey J, Hoffmann M, Schuler G, Mehmel HC, et al The effect of aortic valve replacement on survival. Circulation. 1982;66:1105-10.

3. Lund O. Preoperative risk evaluation and stratification of long-term survival after valve replacement for aortic stenosis. Reasons for earlier operative intervention. Circulation. 1990;82:124-39.

4. Nishimura RA, Otto CM, Bonow RO, Carabello BA, Erwin JP III, Guyton RA et al. 2014 AHA/ACC guideline for the management of patients with valvular heart disease: executive summary: a report of the American College of Cardiology/American Heart Association task force on practice guidelines. J Am Coll Cardiol. 2014;63:2438-88.

5. Iung B, Cachier A, Baron G, Messika-Zeitoun D, Delahaye F, Tornos P, et al. Decision-making in elderly patients with severe aortic stenosis: why are so many denied surgery? Eur Heart J. 2005;26:2714-20.

6. Varadarajan P, Kapoor N, Bansal RC, Pai RG. Clinical profile and natural history of 453 nonsurgically managed patients with severe aortic stenosis. Ann Thorac Surg. 2006;82:2111-5.

7. Bach DS, Siao D, Girard SE, Duvernoy C, McCallister BD Jr, Gualano SK. Evaluation of patients with severe symptomatic aortic stenosis who do not undergo aortic valve replacement: the potential role of subjectively overestimated operative risk. Circ Cardiovasc Qual Outcomes. 2009;2:533-9.

8. Grube E, Laborde JC, Gerckens U, Felderhoff T, Sauren B, Buellesfeld L, et al. Percutaneous implantation of the corevalve self-expanding valve prosthesis in high-risk patients with aortic valve disease: the Siegburg first-in-man study. Circulation. 2006;114:1616-24.

9. Popma JJ, Adams DH, Reardon MJ, Yakubov SJ, Kleiman NS, Heimansohn D, et al. Transcatheter aortic valve replacement using a self-expanding bioprosthesis in patients with severe aortic stenosis at extreme risk for surgery. J Am Coll Cardiol. 2014;63:1972-81.

10. Adams DH, Popma JJ, Reardon MJ, Yakubov SJ, Coselli JS, Deeb GM, et al. Transcatheter aortic-valve replacement with a self-expanding prosthesis. N Engl J Med. 2014;370:1790-8.

11. Reardon MJ, Adams DH, Kleiman NS, Yakubov SJ, Coselli JS, Deeb GM, et al 2-year outcomes in patients undergoing surgical or self-expanding transcatheter aortic valve replacement. J Am Coll Cardiol. 2015;66:113-21.

12. Deeb GM, Chetcuti S, Patel HJ, Grossman M, Yakubov MJ, Kleiman NS, et al Three-year outcomes in high-risk patients who underwent surgical or transcatheter aortic valve replacement. J Am Coll Cardiol. 2016;67:2565-74.

13. Reardon MJ, Adams DH, Coselli JS, Deeb GM, Kleiman NS, Chetcuti S, et al. Self-expanding transcatheter aortic valve replacement using alternative access sites in symptomatic patients with severe aortic stenosis deemed extreme risk of surgery. J Thorac Cardiovasc Surg. 2014;148:2869-76.e1-7.

14. Zorn GL III, Little SH, Tadros P, Deeb GM, Gleason TG, Heiser J, et al. Prosthesis-patient mismatch in high-risk patients with severe aortic stenosis: a randomized trial of a self-expanding prosthesis. J Thorac Cardiovasc Surg. 2016;151:1014-23.

15. Leon MB, Smith CR, Mack M, Miller DC, Moses JW, Svensson LG, et al. Transcatheter aortic-valve implantation for aortic stenosis in patients who cannot undergo surgery. N Engl J Med. 2010;363:1597-607.

16. Smith CR, Leon MB, Mack MJ, Miller DC, Moses JW, Svensson LG, et al Transcatheter versus surgical aortic-valve replacement in high-risk patients. N Engl J Med. 2011;364:2187-98.

17. Leon MB, Smith CR, Mack MJ, Makkar RR, Svensson LG, Kodali SK, et al Transcatheter or surgical aortic-valve replacement in intermediate-risk patients. N Engl J Med. 2016;374:1609-20.

18. Mack MJ, Leon MB, Smith CR, Miller DC, Moses JW, Tuzcu EM, et al. 5-year outcomes of transcatheter aortic valve replacement or surgical aortic valve replacement for high surgical risk patients with aortic stenosis (PARTNER 1): a randomised controlled trial. Lancet. 2015;385:2477-84.

19. Maxwell BG, Wong JK, Miller DC, Lobato RL. Temporal changes in survival after cardiac surgery are associated with the thirty-day mortality benchmark. Health Serv Res. 2014;49:1659-69.

Key Words: aortic stenosis, transcatheter aortic valve replacement, surgical aortic valve replacement, causes of death 


\section{Discussion}

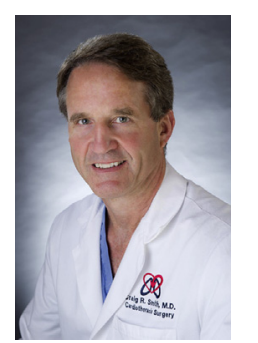

Dr Craig R. Smith (New York, NY). I want to thank the authors for sending me the manuscript in advance. I know very well how hard that is to do with a multi-institutional effort like this.

First, a couple of potentially relevant disclosures. I have leadership roles in the Placement of Aortic Transcatheter Valves (PARTNER) trials, for which I receive reimbursement for customary expenses, which I do not consider a conflict. I should mention that my institution uses both balloon-expanded and self-expanding devices, and I think I am personally agnostic on their comparative virtues. I will do my best to avoid appearing conflicted with respect to the virtues of one trial versus another trial.

You have just heard a very insightful post hoc analysis of a study that is best known, as was mentioned, for being the only randomized trial to show inferiority of surgical aortic valve replacement (SAVR) to transthoracic aortic valve replacement (TAVR). A surgical audience will be naturally inclined to hope for evidence that this trial was somehow wrong. How can a randomized trial go wrong? One way is to have an outcome-quality problem in the control group, and that is why it is important and very admirable for the authors here to dig more deeply into the mortality bulge during what they have called the recovery period that accounts for the significant difference favoring TAVR.

Comparisons are odious, as they say, and I cannot overemphasize how much caution is necessary in comparing clinical trials, even when they are very similar in design. Case in point, the self-expanding TAVR trial just presented was designed to enroll high-risk patients but actually enrolled at the upper end of the intermediate risk range with an Society of Thoracic Surgeons (STS) score of 7.4 versus 11.3 in the high-risk PARTNER 1. But it is probably not fair to call it intermediate risk either. The intermediate risk PARTNER 2 had a lower STS score of 5.8.

To attempt a very rough comparison, we did a similar landmark analysis of not one but both PARTNER trials, and we do not see the recovery phase bulge in mortality reported here comparing time periods within PARTNER, although the outcomes are not conspicuously different comparing PARTNER to this trial. Specifically, the recovery phase mortalities for PARTNER 1 and 2 were $9.5 \%$ and $3.6 \%$, respectively, compared with the $9.7 \%$ reported here.

Dr Reardon presented results for the lower-risk half of the surgical cohort, which lowered the average STS score to 5.1. That subgroup had a 1-year mortality of $14 \%$, which is very similar to PARTNER 2 at $13 \%$, although at 2 years the mortality was more discrepant at $26.3 \%$ versus $17.9 \%$ for PARTNER.
An important counterpoint to this kind of innuendo is to acknowledge that the observed to expected ratio for SAVR in the self-expanding trial was comfortably $<1$ using the STS Predicted Risk For Mortality for the expected variable. So on that relatively quantitative basis there is no support for a claim of poor performance in the control group. However, it must be said that a whiff of concern on that point remains in the recovery phase bulge that you have just heard presented.

There are some important lessons in this presentation, and I am in some respects echoing the points the authors have already made. Note that TAVR had the most early technical mortalities, but those are already disappearing with experience and improvements in technology. TAVR is only getting harder to beat. We have to keep that in mind.

Second, note the frequency of what the authors have called failure to repair and failure to recover. Whether competing against TAVR in a randomized trial or operating on TAVR in eligible patients in the future, as the authors have emphasized, it behooves us to correct the problem as completely as possible and take the best possible care of our patients afterward. Our patients have gone all-in, and so should we. And to you 17- and 19-mm valve fans, maybe you should rethink that approach.

Finally, the difference in discharge to home is very impressive and illustrates a very significant advantage of TAVR.

We know that certain centers have published much lower mortality than what is seen in any of these trials, and that brings me to my first question. In both PARTNER trials there was a broad range of outcomes by site and surgeon, although none were significant outliers. I imagine the same was true in this trial, but did you look at recovery phase results by site?

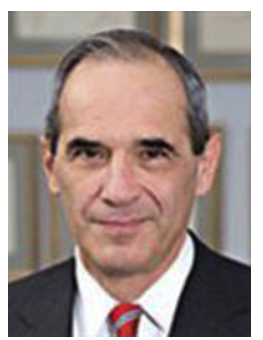

Dr Gaudiani. No, we did not look at recovery phase by site, but using data I did get from Medtronic, we looked at mortality rates from sites that contributed lots of cases compared with sites that contributed only a few, thinking that perhaps the experience of the sites would make a difference in mortality, and it is true. The sites that contributed the most, presumably, did more surgery. One could imagine the Mayo Clinic only having 5 cases in the study because they were not interested in it. In other words, a big center could have only a few patients in.

But it is true that the smaller sites had higher mortality, and they had higher SAVR mortality. It was not statistically significant, but I'll bet you if you wanted to do the statistics a little differently you could have discovered that.

Dr Smith. That is very interesting. Size often makes those comparisons very difficult, I realize. 
In PARTNER, there were a sizable number of concomitant procedures that were performed that were perplexing. Most, like root enlargement or root replacement, were probably necessary and increase risk, but one could argue they offer an opportunity to fix the problem more completely than TAVR can, and so maybe an advantage. Some were hard to imagine being done by any sensible surgeon in a clinical trial, such as carotid endarterectomy. We could not really make much of an influence on concomitant procedures. Were there any notable peculiarities among the concomitant procedures in this trial that could have influenced the recovery phase results?

Dr Gaudiani. We did not see any of that, but on a number of the ones I did I enlarged their outflow tract (Video 1). I think it is one of the things we have to think about.

The two things that struck me about this trial were that many people are taught to put in the valve that fits and do not put in too big a valve because you will get into technical trouble. And that may have been a perfectly good way to think when the teachers historically started doing aortic valve replacement, what is an extremely dangerous operation and the bottom of the aortotomy was the angle of sorrows and all this other stuff that we were taught, but that with experience and over time we now realize it really is not true and that the game, the objective, has to be now to put in a valve that solves the problem, that has $0.85 \mathrm{~cm}^{2} / \mathrm{m}^{2}$, period. Do not even think about doing anything else.

And then we really need a large trial of big incision surgery versus small incision surgery that is randomized to see if less trauma matters in these patients. I am not sure that it is that. It may just be cardiopulmonary bypass and have nothing to do with the size of the skin incision or the bone incision.

But these are the things we now have to think about if we want to stay in the game of aortic valve replacement.

Dr Smith. My last question: Have you learned anything from these results that helped you to improve your approach to the control group management of the completed intermediate and the ongoing low risk trials?

Dr Gaudiani. No. I think that the people who do aortic valve seriously and do a lot of it have already encompassed a lot of these ideas over the past few years, and it is very hard looking on an institution basis to see how many of the surgeons have incorporated these ideas, but I am sure that the future of aortic valve surgery depends on putting in bigger valves and doing less damage at the same time.

Dr Smith. Well said. 


\begin{tabular}{|c|c|c|c|c|c|c|c|c|c|c|c|c|}
\hline \multirow[b]{3}{*}{ Outcome } & \multicolumn{4}{|c|}{$0-30 \mathrm{~d}$} & \multicolumn{4}{|c|}{$31-120 \mathrm{~d}$} & \multicolumn{4}{|c|}{$121-365 \mathrm{~d}$} \\
\hline & \multicolumn{2}{|c|}{ TAVR } & \multicolumn{2}{|c|}{ SAVR } & \multicolumn{2}{|c|}{ TAVR } & \multicolumn{2}{|c|}{ SAVR } & \multicolumn{2}{|c|}{ TAVR } & \multicolumn{2}{|c|}{ SAVR } \\
\hline & $\begin{array}{c}\text { Dead } \\
(\mathbf{n}=\mathbf{1 3})\end{array}$ & $\begin{array}{c}\text { Alive } \\
(\mathrm{n}=\mathbf{3 7 8})\end{array}$ & $\begin{array}{c}\text { Dead } \\
(\mathrm{n}=16)\end{array}$ & $\begin{array}{c}\text { Alive } \\
(\mathrm{n}=\mathbf{3 4 2}) \\
\end{array}$ & $\begin{array}{c}\text { Dead } \\
(\mathbf{n}=15)\end{array}$ & $\begin{array}{c}\text { Alive } \\
(\mathrm{n}=363)\end{array}$ & $\begin{array}{c}\text { Dead } \\
(\mathbf{n}=27)\end{array}$ & $\begin{array}{c}\text { Alive } \\
(\mathbf{n}=\mathbf{3 1 5})\end{array}$ & $\begin{array}{c}\text { Dead } \\
(\mathbf{n}=27)\end{array}$ & $\begin{array}{c}\text { Alive } \\
(\mathbf{n}=\mathbf{3 3 5})\end{array}$ & $\begin{array}{c}\text { Dead } \\
(\mathbf{n}=\mathbf{2 4})\end{array}$ & $\begin{array}{c}\begin{array}{c}\text { Alive } \\
(\mathbf{n}=\mathbf{2 8 9})\end{array} \\
\end{array}$ \\
\hline Age, y & $85.5 \pm 7.3$ & $83.1 \pm 7.1$ & $84.2 \pm 6.9$ & $83.2 \pm 6.3$ & $82.7 \pm 9.5$ & $83.1 \pm 7.0$ & $85.0 \pm 5.7$ & $83.1 \pm 6.4$ & $83.1 \pm 6.8$ & $83.1 \pm 7.0$ & $83.5 \pm 5.4$ & $83.0 \pm 6.4$ \\
\hline Men & $6(46.2)$ & $201(53.2)$ & $6(50.0)$ & $179(52.3)$ & $10(66.7)$ & $191(52.6)$ & $14(51.9)$ & $165(52.4)$ & $16(59.3)$ & $175(52.2)$ & $9(37.5)$ & $156(54.0)$ \\
\hline STS score, $\%$ & $9.4 \pm 4.7$ & $7.2 \pm 2.9$ & $9.1 \pm 4.7$ & $7.5 \pm 3.3$ & $7.8 \pm 2.9$ & $7.2 \pm 2.9$ & $7.9 \pm 2.8$ & $7.4 \pm 3.3$ & $7.8 \pm 2.2$ & $7.2 \pm 3.0$ & $8.4 \pm 4.0$ & $7.3 \pm 3.2$ \\
\hline $\begin{array}{l}\text { Chronic kidney } \\
\text { disease }\end{array}$ & $3(23.1)$ & $45 / 374(12.0)$ & $3(18.8)$ & $42 / 337(12.5)$ & $2(13.3)$ & $43 / 359(12.0)$ & 7 (25.9) & $35 / 310(11.3)^{*}$ & $4 / 25(16.0)$ & $39 / 333(11.7)$ & $5(20.8)$ & $29 / 284(10.2)$ \\
\hline $\begin{array}{l}\text { Peripheral } \\
\text { vascular } \\
\text { disease }\end{array}$ & $\begin{array}{l}9 / 12 \\
(75.0)^{*}\end{array}$ & $150 / 376(39.9)$ & $9(56.3)$ & $140 / 340(41.2)$ & $7 / 14(50.0)$ & $143 / 362(39.5)$ & $8(29.6)$ & $132 / 313(42.2)$ & $8(29.6)$ & $134 / 334(40.1)$ & $14(58.3)$ & $117 / 287(40.8)$ \\
\hline $\begin{array}{l}\text { Chronic lung } \\
\text { disease }\end{array}$ & $5(38.5)$ & $170(45.0)$ & $6(37.5)$ & $155(45.3)$ & $8(53.3)$ & $162(44.6)$ & $14(51.9)$ & $141(44.8)$ & $14(51.9)$ & $148(44.2)$ & $14(58.3)$ & $127(43.9)$ \\
\hline $\begin{array}{l}\text { Coronary artery } \\
\text { disease }\end{array}$ & $9(69.2)$ & $286(75.7)$ & $13(81.3)$ & $259(75.7)$ & $12(80.0)$ & $274(75.5)$ & $19(70.4)$ & $240(76.2)$ & $21(77.8)$ & $253(75.5)$ & $16(66.7)$ & $222(76.8)$ \\
\hline Pre-existing PPI & $4(30.8)$ & $87(23.0)$ & $8(50.0)^{*}$ & 68 (19.9) & $4(26.7)$ & $83(22.9)$ & $5(18.5)$ & $63(20.0)$ & $11(40.7)$ & $72(21.5)^{*}$ & $7(29.2)$ & $55(19.0)$ \\
\hline $\begin{array}{l}\text { Atrial fibrillation/ } \\
\text { flutter }\end{array}$ & $4(30.8)$ & $156 / 377(41.4)$ & $8(56.3)$ & $155 / 342(45.3)$ & $6 / 14(42.9)$ & $150(41.3)$ & $14(51.9)$ & $141(44.8)$ & $18(66.7)$ & $131(39.1)^{*}$ & $15(62.5)$ & $126(43.6)$ \\
\hline $\begin{array}{l}\text { Severe aortic } \\
\text { calcification }\end{array}$ & $2(15.4)$ & 45 (11.9) & $1(6.3)$ & $41(12.0)$ & $2(13.3)$ & 43 (11.8) & $2(7.4)$ & 39 (12.4) & $5(18.5)$ & $37(11.0)$ & $1(4.2)$ & $38(13.1)$ \\
\hline Home oxygen & $2(15.4)$ & $48 / 377(12.7)$ & $1(6.3)$ & 40 (11.7) & $1(6.7)$ & 47/362 (13.0) & $5(18.5)$ & $35(11.1)$ & $7(25.9)$ & $40 / 334(12.0)^{*}$ & $6(25.0)$ & $29(10.0)^{*}$ \\
\hline $\begin{array}{l}\text { Anemia requiring } \\
\text { transfusion }\end{array}$ & $1(7.7)$ & $68 / 367(18.5)$ & $2(13.3)$ & $53(16.0)$ & $6(40.0)$ & $62 / 352(17.6)^{*}$ & $7 / 24(29.2)$ & 46/307 (15.0) & $9 / 25(36.0)^{*}$ & $53 / 326(16.3)$ & $5 / 23(21.7)$ & $41 / 282(14.5)$ \\
\hline Albumin $<3.3 \mathrm{~g} / \mathrm{dL}$ & $2(15.4)$ & $57 / 374(15.2)$ & $2(12.5)$ & $52 / 333(15.6)$ & $4(26.7)$ & $53 / 359(14.8)$ & $9(33.3)$ & $43 / 306(14.1)^{*}$ & $8(29.6)^{*}$ & 45/331 (13.6) & $4(16.7)$ & $39 / 280(13.9)$ \\
\hline $\begin{array}{l}\text { Unplanned weight } \\
\text { loss }\end{array}$ & $3(23.1)$ & $32(8.5)$ & $0(0.0)$ & $25(7.3)$ & $1(6.7)$ & $31(8.5)$ & $6(22.2)$ & $19(6.0)^{*}$ & $3(11.1)$ & $28(8.4)$ & $1(4.2)$ & $17(5.9)$ \\
\hline $\begin{array}{l}\text { 5-m gait } \\
\text { speed }>6 \mathrm{~s}\end{array}$ & $7 / 10(70.0)$ & 268/337 (79.5) & $9 / 13(69.2)$ & $242 / 299(80.9)$ & $11 / 14(78.6)$ & $257 / 323(79.6)$ & $19 / 23(82.6)$ & $223 / 276(80.8)$ & $18 / 22(81.8)$ & $238 / 300(79.3)$ & $19 / 20(95.0)$ & $202 / 254(79.5)$ \\
\hline Falls in past $6 \mathrm{mo}$ & $6(46.2)^{*}$ & $66 / 377(17.5)$ & $2(12.5)$ & $63(18.4)$ & $3(20.0)$ & 63/362 (17.4) & $9(33.3)^{*}$ & $54(17.1)$ & $9(33.3)^{*}$ & $54 / 334(16.2)$ & $4(16.7)$ & $49(17.0)$ \\
\hline $\begin{array}{l}\geq 2 \mathrm{Katz} \dagger \text { ADL } \\
\text { deficits }\end{array}$ & $1(7.7)$ & $22(5.8)$ & $2(12.5)$ & $22(6.4)$ & $1(6.7)$ & $21(5.8)$ & $4(14.8)$ & $18(5.7)$ & $3(11.1)$ & $18(5.4)$ & $5(20.8)^{*}$ & $13(4.5)$ \\
\hline \multicolumn{13}{|c|}{ Procedural outcome } \\
\hline $\begin{array}{l}\text { Procedure } \\
\text { time, min }\end{array}$ & $56.8 \pm 24.3$ & $60.3 \pm 35.6$ & $238.6 \pm 112.1$ & $220.1 \pm 83.3$ & $56.1 \pm 29.4$ & $60.5 \pm 35.9$ & $224.9 \pm 75.0$ & $219.7 \pm 84.1$ & $65.0 \pm 40.5$ & $60.3 \pm 35.5$ & $203.9 \pm 63.6$ & $220.8 \pm 85.5$ \\
\hline $\begin{array}{l}\text { TAV delivery } \\
\text { time, min }\end{array}$ & $16.9 \pm 20.5$ & $13.6 \pm 11.2$ & NA & NA & $12.7 \pm 13.0$ & $13.6 \pm 11.1$ & NA & NA & $14.3 \pm 11.5$ & $13.6 \pm 11.1$ & NA & NA \\
\hline CPS time, min & NA & NA & $107.5 \pm 68.5$ & $103.8 \pm 44.6$ & NA & NA & $105.1 \pm 43.4$ & $103.7 \pm 44.8$ & NA & NA & $95.7 \pm 33.0$ & $104.2 \pm 45.5$ \\
\hline $\begin{array}{l}\text { Crossclamp } \\
\text { time, min }\end{array}$ & NA & NA & $80.4 \pm 49.0$ & $73.7 \pm 30.4$ & NA & NA & $81.7 \pm 41.3$ & $73.1 \pm 29.3$ & NA & NA & $68.5 \pm 25.6$ & $73.4 \pm 29.7$ \\
\hline
\end{tabular}

Data are presented as mean \pm standard deviation, $\mathrm{n}(\%)$, or $\mathrm{n} / \mathrm{N}(\%)$. TAVR, Transcatheter aortic valve replacement; SAVR, surgical aortic valve replacement; STS, Society of Thoracic Surgeons; PPI, permanent pacemaker implantation; $A D L$, activities of daily living; $T A V$, transcatheter aortic valve; $N A$, not available; $C P S$, cardiopulmonary bypass support. $* P<.05$ for dead versus alive. $\dagger$ Katz $S$. Assessing self-maintenance: activities of daily living, mobility, and instrumental activities of daily living. J Am Geriatr Soc. 1983;31:721-7. 